\title{
IgA vasculitis, formerly known as Henoch-Schönlein purpura - the most common vasculitis in children
}

\author{
Majka Jaszczura, Katarzyna Dyga, Aleksandra Bryłka, Anna Góra, Edyta Machura \\ Department of Paediatrics, School of Medicine with the Division of Dentistry in Zabrze, Medical University of Silesia, Zabrze, \\ Poland
}

\section{ABSTRACT}

\begin{abstract}
Henoch-Schönlein purpura (HSP) is the most common systemic vasculitis in children. It belongs to the group of small-vessel vasculitis associated with immune complexes, and the proper term is IgA vasculitis (IgAV). In HSP in the wall of small vessels, deposits of immune complexes composed of IgA1 and C3 complement component are found. The incidence of HSP is estimated at 3-26.7/100,000 children per year. The changes most often affect the skin, lower limbs, digestive tract, and kidneys and are accompanied by arthralgia and arthritis. In this review article we pay attention to the pathogenesis, possible clinical manifestations, irregularities in laboratory tests, and proper management of patients with HSP. The treatment should depend on the clinical condition of the patient and is primarily symptomatic. Good knowledge of the differentiation of clinical symptoms allows for quick diagnosis and the qualification of patients for appropriate supervision.
\end{abstract}

\section{KEY WORDS:}

children, vasculitis, nephropathy, purpura.

\section{INTRODUCTION}

Henoch-Schönlein purpura (HSP) is the most common systemic vasculitis in developmental age. The first case of a small boy with arthritis, haematuria, melena, and haemorrhagic rash was described in 1802 by Dr. William Heberden. The common name of the disease comes from Johann Schönlein and his student Eduard Henoch, who combined all the symptoms. The name Henoch-Schönlein purpura is of historic importance today; the proper term is IgA vasculitis (immunoglobulin A vasculitis IgAV). According to the new nomenclature established during the International Chapel Hill Consensus Conference 2012 (CHCC 2012), it belongs to the small vessel vasculitis group associated with immune complexes [1]. In HSP in the wall of small vessels (mainly capillaries, venules, and arterioles), deposits of immune complexes composed primarily of IgA1 and C3 complement component are found. The changes most often affect the skin, lower limbs, digestive tract, and kidneys and are accompanied by arthralgia and arthritis.

\section{EPIDEMIOLOGY}

The incidence of HSP is estimated at 3-26.7/100,000 children per year, depending on the country studied $[2,3]$; in adults it is nearly a hundredfold lower. The onset of the disease is between three and 15 years of age, with the highest incidence between four and six years of age. It is believed that the later age of onset may be a risk factor for developing nephropathy $[4,5]$. The disease is more common in boys (index M : F 1.8-1) [6-8], but there are also reports that the prevalence is similar in both sexes [6]. It occurs in children regardless of race, but is much

\section{ADDRESS FOR CORRESPONDENCE:}

Majka Jaszczura, Department of Paediatrics, School of Medicine with the Division of Dentistry in Zabrze,

Medical University of Silesia, 13-15 3 Maja St., 41-800 Zabrze, Poland, e-mail: tleni@wp.pl 
TABLE 1. EULAR/PRINTO/PRES criteria for Henoch-Schönlein purpura diagnosis

\begin{tabular}{|l|l|}
\hline Criterion & Description \\
\hline Purpura & Palpable purpura or petechiae, with lower limb predominance, not related to thrombocytopaenia \\
\hline Abdominal pain & Diffuse abdominal colicky pain with acute onset, may include intussusception and gastrointestinal bleeding \\
\hline Histopathology & $\begin{array}{l}\text { Leukocytoclastic vasculitis with predominant IgA deposit or proliferative glomerulonephritis with predominant } \\
\text { IgA deposit }\end{array}$ \\
\hline Arthritis/arthralgias & $\begin{array}{l}\text { Arthritis of acute onset defined as joint swelling or joint pain with limitation of motion. } \\
\text { Arthralgia of acute onset defined as joint pain without joint swelling or limitation of motion }\end{array}$ \\
\hline Renal involvement & $\begin{array}{l}\text { Proteinuria }>0.3 \mathrm{~g} / 24 \mathrm{~h} \text { or }>30 \mathrm{mmol} / \mathrm{mg} \text { of urine albumin/creatinine ratio on a spot morning sample. } \\
\text { Haematuria or red blood cell casts }>5 \mathrm{RBC} / \mathrm{high} \text { power field or red blood cell casts in the urinary sediment } \\
\text { or } \geq++ \text { on dipstick }\end{array}$ \\
\hline
\end{tabular}

For purpura with atypical distribution a demonstration of an IgA deposit in a biopsy is required

more common in Asia, where the incidence is estimated at 70/100,000/year [7] and is very rare among the black race [2]. The prevalence of diseases in the autumn and winter suggests a possible connection with infectious factors $[8,9]$, especially with the history of upper respiratory tract infections.

\section{CRITERIA FOR DIAGNOSIS}

New guidelines for HSP recognition were published in 2010. This is a consensus developed jointly by the European League Against Rheumatism (EULAR), the Paediatric Rheumatology International Trials Organisation (PRINTO), and the Paediatric Rheumatology European Society (PRES), which changes the previously used American College of Rheumatology (ACR) criteria from 1990 $[10,11]$. The new criteria, as a prerequisite for diagnosis, include a palpable non-thrombocytopenic skin purpura or ecchymosis localised mainly on the lower limbs and fulfilment of at least one of the other criteria presented in Table 1. One of the ACR criteria was a biopsy showing granulocytes in the vessel wall; however, it was characterised by low specificity in the paediatric population and was rarely performed. Currently, a biopsy is reserved for all dubious cases with atypical distribution of skin lesions. The EULAR/PRINTO/PRES criteria show higher sensitivity and specificity in the paediatric population compared to the ACR criteria $[10,12]$.

\section{AETIOLOGY AND PATHOGENESIS}

The change of naming is to a large extent associated with a better understanding of the pathogenesis of the disease. In HSP, in the wall of small vessels, deposits of immunological complexes built primarily of immunoglobulin A1 (IgA1) and C 3 component of the complement system are found, which have an undeniable connection with the development of the disease. In patients with HSP, the presence of tissue compatibility antigens was more frequent: HLA-DRB $1^{\star} 01$ and HLA-DRB1 ${ }^{\star} 11$, while HLA- $B^{\star} 41$ :02 proved to be a marker of disease susceptibility $[13,14]$.
Recent reports assume that the pathogenesis of HSP includes complexes formed by IgA with a soluble receptor for this immunoglobulin, FcaRI [15]. FcaRI is a bifunctional receptor that, depending on whether it is activated by monomeric $\operatorname{Ig} \mathrm{A}$ or by immunological complexes containing IgA, may promote processes that inhibit the inflammatory response or, conversely, enhance the inflammatory process by inducing migration and activation of neutrophils. The effects of IgA through the FcaRI receptor have been demonstrated in many diseases associated with the production of IgA autoantibodies, such as: IgA linear bullous dermatosis, rheumatoid arthritis, and ulcerative colitis [16].

Another element that is pointed out in the pathogenesis of HSP is abnormal glycosylation of the IgA1 hinge region, which is associated with genetic predisposition and/ or coexisting infection [17]. Abnormal IgA1 molecule in HSP is galactose deficient - the so-called galactose-deficient IgA1 (Gd-IgA1) are formed, which function as neoepitopes against which immunoglobulin $\mathrm{G}(\mathrm{IgG})$ autoantibodies may be created $[18,19]$. GdIgA1-IgG complexes are primarily associated with HSP nephropathy, the formation of these antibodies, as well as their role in the systemic inflammatory process in Henoch-Schönlein purpura are poorly understood.

Anti-endothelial cell antibodies (AECA) may also play the role in the pathogenesis of HSP. It is assumed that some microorganisms have antigenic structures similar to antigens of the walls of blood vessels, and the infection leads to the production of cross-reactive AECA [20]. These antibodies, by combining with antigens on the surface of endothelial cells, lead to vessel damage by antibody-dependent cell cytotoxicity or complement dependent cytotoxicity [21]. This leads to an increased influx of neutrophils and secretion of, among others, interleukin-8 (IL-8) and leukotriene B4 (LTB4), which further enhance the migration of granulocytes and cause damage to the vascular endothelium. The abovementioned immune complexes formed as a result of an abnormal response to antigenic stimulation accumulate in the vascular walls and activate the complement cascade (especially C5a and C3a components), ultimately leading to the recruitment 
TABLE 2. Main pathogens associated with Henoch-Schönlein purpura [29]

\begin{tabular}{|c|c|}
\hline Bacteria & $\begin{array}{l}\text { Streptococcus pyogenes } \\
\text { Neisseria meningitidis } \\
\text { Mycoplasma pneumoniae } \\
\text { Bartonella henselae } \\
\text { Helicobacter pylori } \\
\text { Salmonella enteritidis } \\
\text { Mycobacterium tuberculosis } \\
\text { Staphylococcus aureus } \\
\text { Chlamydophila pneumoniae } \\
\text { Campylobacter jejuni } \\
\text { Kingella kingae }\end{array}$ \\
\hline Viruses & $\begin{array}{l}\text { Parvovirus B19 } \\
\text { Hepatitis B virus } \\
\text { Hepatitis A virus } \\
\text { Hepatitis C virus } \\
\text { Varicella-Zoster virus }\end{array}$ \\
\hline Protozoa & $\begin{array}{l}\text { Giardia intestinalis } \\
\text { Trichomonas hominis } \\
\text { Ascaris lumbricoides } \\
\text { Entamoeba histolytica } \\
\text { Plasmodium falciparum }\end{array}$ \\
\hline
\end{tabular}

of granulocytes and macrophages to the site of inflammation [22]. IgA antibodies may activate the complement system on an alternative pathway, and recent studies have shown that also on the lectin pathway, through the linking with mannose binding lectin (MBL) [23].

For many years, it has been believed that among pro-inflammatory cytokines, tumour necrosis factor- $\alpha$ (TNF- $\alpha$ ), interleukin-6 (IL-6), and IL-8 play an important role in the pathogenesis of HSP, which may affect the accumulation of IgA deposits in the vascular wall. IL-6 is one of the most important pro-inflammatory cytokines, it stimulates acute-phase protein synthesis, and induces leukocytosis and thrombocytosis, leading to the synthesis of IL-8, which stimulates the migration of neutrophils, monocytes, and T lymphocytes, inducing neutrophil adhesion to the endothelium [24]. It is suggested that elevated interleukin-33 (IL-33) concentration may contribute to increased production of IgA autoantibodies and correlate with the severity of the disease $[25,26]$. Few studies indicate that an immune response involving Th17 lymphocytes may have a large contribution to the pathogenesis of HSP, which is a lymphocyte population whose development and maturation synergistically stimulates interleukin-18 (IL-18) and interleukin-23 (IL-23). Immunological reactions caused by Th17 lymphocytes, i.e. by their production of interleukin-17 (IL-17), are of particular importance for combating extracellular infections; they are responsible for the rapid development of inflammatory response and neutrophil influx [27, 28]. All these cytokines stimulate neutrophil migration, adhesion to the vascular endothelium, and their infiltration into the perivascular space, resulting in the development of leukocytoclastic vasculitis.
Considering the fact that HSP occurs more frequently in the infectious period, it is widely believed that the possible mechanisms of disease development described above may be the result of an abnormal response of the immune system to various types of antigens. 30-65\% of cases are preceded by infection of the upper respiratory tract. So far, a trigger agent has not been identified. Cross-reactivity to bacterial and viral antigens is highly probable (Table 2) [29]. Other possible triggers are drugs (angiotensin converting enzyme inhibitors - ACEI, non-steroidal anti-inflammatory drugs - NSAIDs, antibiotics) [30, 31], vaccinations (against influenza, hepatitis A and B) [32, 33], toxins (e.g. insects), food allergens, and tumour antigens (cancers of lung, breasts, prostate, oesophagus, large intestine, lymphoma) [34-37].

\section{CLINICAL MANIFESTATION}

HSP with a typical course is a relatively easily diagnosed disease. Classically it is characterised by the presence of petechiae of the skin, which may be accompanied by inflammation of small vessels of the gastrointestinal tract and kidneys, and inflammation/pain of the joints. Symptoms from other organs are very rarely observed. Some patients may have more relapses with new skin lesions. Most sources agree that over $95 \%$ of paediatric patients recover completely without sequelae.

\section{PETECHIAL PURPURA}

Palpable purpura or petechiae (Fig. 1, Fig. 2) are the most characteristic symptoms and occur in all children with HSP. Skin changes are varied, they take the form of petechiae, but also large haemorrhagic ecchymoses; skin necrosis is rare ( $<5 \%$ of cases). In addition, erythema, spots, urticaria, or vesicular and haemorrhagic changes may occur. The rash is the first symptom of the disease in about $70 \%$ of cases, and its polymorphic character is more typical in the course of the disease in children [38]. Skin lesions are mainly located on the lower limbs: feet, lower legs, and buttocks, and much less frequently in the upper half of the body. Sometimes they are accompanied by subcutaneous tissue oedema and tenderness, which may be misinterpreted as erythema nodosum. The eruptions disappear without a trace. In $25-33 \%$ of cases, subsequent seeding of skin lesions is observed. Recurrence of the disease is more common in older children ( $>8$ years of age) and in children with kidney involvement; it may also be associated with a greater severity of renal changes [39-41].

\section{ARTHRITIS/ARTHRALGIA}

According to the literature, joint symptoms are the second most common symptom in HSP, occurring in as much as $75 \%$ of cases $[42,43]$. Arthritis is usually oli- 


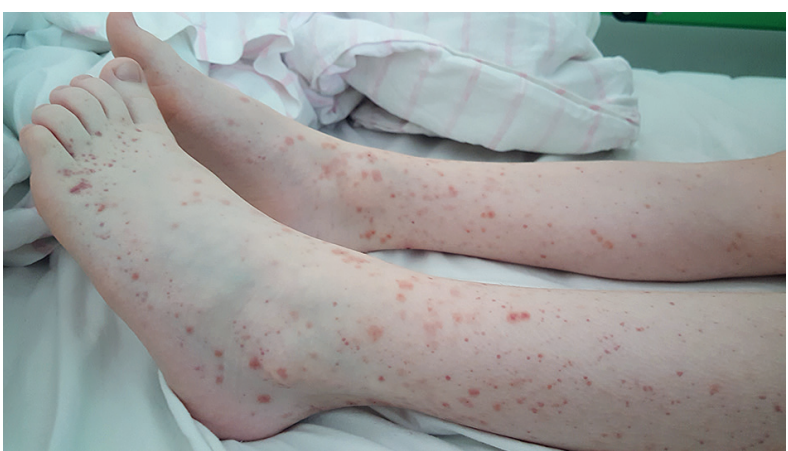

FIGURE 1. Differentiated ecchymotic changes in the course of Henoch-Schönlein purpura; swelling of the ankle joint is also visible in Figure 2

goarticular, transient, self-limiting, and affects large joints of the lower limbs (knee, ankle). Small, hand, wrists, or elbow joints are much less frequently involved. Isolated pain, but also swelling, tenderness, and increased warmth, usually without exudate, may also appear. Reluctance to walk may be the first symptom in young children. In $\sim 15 \%$ of cases, joint changes may precede the occurrence of other symptoms of the disease [43].

\section{GASTROINTESTINAL TRACT INVOLVEMENT}

Involvement of the gastrointestinal tract occurs in $50-70 \%$ of patients $[43,44]$. The most common symptom of the digestive tract is colic abdominal pain, usually diffuse, localised near the navel, intensifying after meals. Pain complaints may be accompanied by nausea, vomiting (sometimes bloody or black), and diarrhoea with blood. These symptoms are caused by submucosal or mucosal blood extravasation and oedema, and they most commonly concern the proximal section of the small intestine and can lead to ulceration of the intestinal wall, perforation and bleeding into the lumen of the tract. Other rare but serious complications from the gastrointestinal tract include: intussusception, intestinal necrosis, acute pancreatitis, enteropathy with protein loss, cholecystitis, intestinal stenosis, and duodenum obstruction [42, 45, 46]. Strong pain in the abdominal cavity, especially in the absence of a rash, can lead to misdiagnosis, suspicion of an acute abdomen, and unnecessary surgical intervention [47]. In $10 \%$ of cases, abdominal symptoms may be the first symptom of the disease.

\section{RENAL INVOLVEMENT}

It is the most dangerous complication of HSP. Literature data on the incidence of renal involvement are not consistent as they show a large range from $10-60 \%$. Isolated haematuria, which appears within four weeks of the onset of the disease, is most often observed. There may be various degrees of proteinuria, including nephrotic syndrome (proteinuria $>3.5 \mathrm{~g} /$ day). The severity

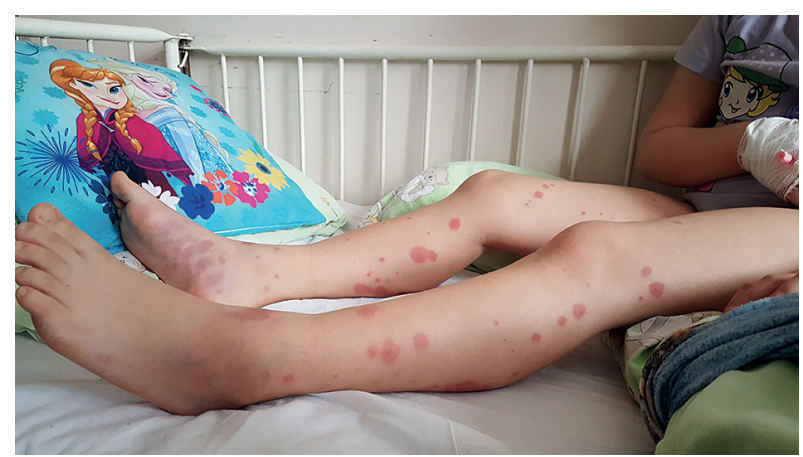

FIGURE 2. Differentiated ecchymotic changes in the course of Henoch-Schönlein purpura; swelling of the ankle joint is also visible in Figure 1

of proteinuria in the acute phase of the disease does not correlate with the likelihood of subsequent kidney damage, but its non-occurrence is a good prognostic factor [48]. The factors of unfavourable prognosis are as follows: proteinuria occurring from the beginning of the disease, age $>7$ years, obesity, long-term purpura, and male sex $[49,50]$. In most cases, kidney function is preserved, but some patients may experience rapidly progressive glomerulonephritis. Hypertension may develop at any stage of the disease. The risk of developing chronic kidney disease is higher in adults and it amounts to $\sim 30 \%$, while in children it does not exceed $7 \%$. However, it should be remembered that renal involvement may not always appear at the beginning of the disease. Therefore, current guidelines recommend observation of patients and periodic checks, including blood pressure measurement and urinalysis for the subsequent six months $[49,51]$.

\section{RARE MANIFESTATIONS}

$10-20 \%$ of boys with HSP may suffer from inflammation of the testicles with pain and swelling of the scrotum, which requires differentiation with testicle torsion or other reasons, e.g. acute scrotum, and sometimes even leads to surgery [52].

In the course of the disease, we can also observe symptoms of the nervous system $(<1 \%$ of cases in children): headaches, behavioural disorders, visual and speech disorders, disturbances in consciousness, convulsions, and focal symptoms. Several cases of Posterior Reversible Encephalopathy Syndrome (PRES) have been described, which may be the result of inflammation of the nervous system vessels or hypertension [53]. Hypertension that is observed in patients with HSP may lead to central nervous system (CNS) haemorrhage. In patients with neurological symptoms, it is necessary to perform CNS imaging examinations which, apart from bleeding, may reveal foci of oedema mainly in the subcortical region of the white matter of parieto-occipital region.

Inflammation and muscle pain, especially of the lower limbs (pain is caused by bleeding into the muscle or 
TABLE 3. Differentiation of Henoch-Schönlein purpura

\begin{tabular}{|l|l|}
\hline Symptom & Disease \\
\hline Purpura & Sepsis \\
& Thrombocytopenic purpura \\
& Haemolytic-uremic syndrome \\
& Myeloid proliferation \\
& Coagulopathies \\
& Acute haemorrhagic oedema of infants \\
& (Finkelstein syndrome) \\
& Gardner-Diamond syndrome \\
& Drug reaction \\
& Dermatomyositis \\
& Vasculitis with hypersensitivity \\
& Infective endocarditis \\
\hline Arthritis/arthralgias & Lupus erythematosus \\
& Juvenile idiopathic arthritis \\
& Nodular polyarteritis \\
& Rheumatic fever \\
& Mixed connective tissue disease \\
& Bacterial arthritis \\
\hline Abdominal pain & Aappendicitis \\
& Intussusception/obstruction \\
Crohn disease
\end{tabular}

ischaemia resulting from necrotising vasculitis) are very rare [54]. Myocardial involvement may occur in the form of myocarditis, pericarditis, atrioventricular block, and myocardial infarction and may lead to life-threatening cardiovascular failure. Symptoms include chest pain, exercise dyspnoea, decreased exercise tolerance, and peripheral oedema [55]. Other, sporadic manifestations include diffuse vesicular bleeding and anterior uveitis.

\section{ADDITIONAL TESTS}

Laboratory tests do not allow unambiguous confirmation of the diagnosis, and they only have an auxiliary function. They enable the exclusion of other disease entities, assessment of the patient's condition, treatment monitoring, and detection of possible complications. In some patients with HSP, increased inflammatory parameters are found - leukocytosis, increased concentration of C-reactive protein, and higher values of the neutrophil-lymphocyte ratio (NLR). Approximately half of the patients have elevated levels of IgA and partially reduced levels of C3 component of the complement system [8]; sometimes the presence of an IgA-class rheumatoid factor (RF) and antineutrophilic cytoplasmic antibody (ANA) of IgA class is demonstrated. Elevated values of D-dimers and fibrinogen are often observed, while clotting times are normal. In the case of involvement of the gastrointestinal tract, we obtain a positive faecal occult blood test (FOBT). The systematic performance of a general urine test, monitoring of creatinine and measurement of blood pressure are key elements for detection of possible renal complications.

\section{DIFFERENTIATION}

Diseases to be considered for differentiation are shown in Table 3.

\section{TREATMENT}

To date, no clear guidelines for the treatment of HSP have been established. The management should depend on the clinical condition of the patient and is primarily symptomatic. In the case of skin lesions, haemostatic drugs (etamsylate, rutoside) are used in an adjunct way, despite the lack of conclusive scientific evidence for their effectiveness. In patients with joint pain, a well-balanced lifestyle, limitation of physical activity, and supply of NSAIDs are recommended. In the case of combined use of NSAIDs and steroid therapy, prevention of gastric ulcer and the use of proton pump inhibitors (PPI) should be borne in mind. ACE-I or angiotensin receptor blockers (ARBs) are used to treat hypertension. Due to their nephroprotective effect, reducing proteinuria and slowing the progression of renal failure, they are the first-choice drugs. They should also be used in children with nephritis and persistent proteinuria of $0.5-1 \mathrm{~g} /$ day/1.73 $\mathrm{m}^{2}$ [56].

A frequent infectious aetiology should be taken into account and in antibacterial or antiviral treatment should be included in appropriate cases. Some children with severe and recurrent purpura may require tonsillectomy as a deletion of the latent source of chronic infection [56].

The most controversial and contradictory reports concern treatment with glucocorticosteroids (GCS). It has not been clearly demonstrated that they shorten the duration of the disease or reduce the risk of relapse. Single reports indicate that skin lesions and joint discomfort are more quickly resolved after using prednisone $[57,58]$. The advantage of steroid therapy over placebo in long-term prevention of renal complications has not been demonstrated [59]. In some patients, early use of GCS may reduce the risk of serious gastrointestinal complications, reduce the need for surgical intervention or endoscopic examinations, and reduce the consumption of analgesics [60].

The current state of knowledge does not allow for the creation of unambiguous guidelines for treatment with GCS. The use of prednisone $(1-2 \mathrm{mg} / \mathrm{kg} /$ day for 1-2 weeks with an appropriate period of gradual dose reduction) should be considered in the case of severe abdominal pain, joint pain, and severe skin lesions [57]. Children with renal symptoms, especially nephrotic syndrome, nephritic syndrome, and rapidly deteriorating re- 
nal function, should be referred to the reference centre. In HSP inflammation of the kidneys, the effectiveness of intravenous methylprednisolone pulses has been demonstrated. In severe cases, other therapies are also applied with the use of the following: cyclosporine $\mathrm{A}$, mofetil mycophenolate, azathioprine, cyclophosphamide, and intravenous immunoglobulin infusions (IVIG). In rapidly progressing glomerulonephritis, multi-drug therapy and plasmapheresis are used.

\section{CONCLUSIONS}

In most cases, HSP is a disease with a mild, self-limiting course and good prognosis. Only nephritis can be associated with more serious consequences in the future; fortunately only $1-3 \%$ of patients develop the end stage of chronic kidney disease [61]. Good knowledge of the differentiation of clinical symptoms allows for quick diagnosis and the qualification of patients for appropriate supervision. Further research is necessary to find effective therapy that prevents the development of chronic kidney disease.

\section{DISCLOSURE}

The authors declare no conflict of interest.

\section{REFERENCES}

1. Jennette JC, Falk RJ, Bacon PA, et al. 2012 revised International Chapel Hill Consensus Conference Nomenclature of Vasculitides. Arthritis Rheum 2013; 65: 1-11.

2. Piram M, Mahr A. Epidemiology of immunoglobulin A vasculitis (Henoch-Schonlein): current state of knowledge. Curr Opin Rheumatol 2013; 25: 171-178.

3. Aalberse J, Dolman K, Ramnath G, et al. Henoch Schonlein purpura in children: an epidemiological study among Dutch paediatricians on incidence and diagnostic criteria. Ann Rheum Dis 2007; 66: 1648-1650.

4. Peru H, Soylemezoglu O, Bakkaloglu SA, et al. Henoch Schonlein purpura in childhood: clinical analysis of 254 cases over a 3-year period. Clin Rheumatol 2008; 27: 1087-1092.

5. Ghrahani R, Ledika MA, Sapartini G, et al. Age of onset as a risk factor of renal involvement in Henoch-Schönlein purpura. Asia Pac Allergy 2014; 4: 42-47.

6. González LM, Janniger CK, Schwartz RA. Pediatric Henoch-Schönlein purpura. Int J Dermatol 2009; 48: 1157-1165.

7. Gardner-Medwin JM, Dolezalova P, Cummins C, et al. Incidence of Henoch-Schönlein purpura, Kawasaki disease, and rare vasculitides in children of different ethnic origins. Lancet 2002; 360: 1197-1202.

8. Trapani S, Micheli A, Grisolia F, et al. Henoch Schonlein purpura in childhood: epidemiological and clinical analysis of 150 cases over a 5-year period and review of literature. Semin Arthritis Rheum 2005; 35: 143-153.

9. Atkinson SR, Barker DJ. Seasonal distribution of Henoch-Schönlein purpura. Br J Prev Soc Med 1976; 30: 22-25.

10. Ozen S, Pistorio A, Iusan SM, et al. EULAR/PRINTO/PRES criteria for Henoch-Schönlein purpura, childhood polyarteritis nodosa, childhood Wegener granulomatosis and childhood Takayasu arteritis: Ankara 2008. Part II: Final classification criteria. Ann Rheum Dis 2010; 69: 798-806.
11. Mills JA, Michel BA, Bloch DA, et al. The American College of Rheumatology 1990 criteria for the classification of Henoch-Schönlein purpura. Arthritis Rheum 1990; 33: 1114-1121.

12. Yang $\mathrm{YH}, \mathrm{Yu} \mathrm{HH}$, Chiang BL. The diagnosis and classification of Henoch-Schönlein purpura: an updated review. Autoimmun Rev 2014; 13: 355-358.

13. He X, Yu C, Zhao P, et al. The genetics of Henoch-Schönlein purpura: a systematic review and meta-analysis. Rheumatol Int 2013; 33: 1387-1395.

14. López-Mejías R, Genre F, Pérez BS, et al. Association of HLA-B ${ }^{\star} 41: 02$ with Henoch-Schönlein Purpura (IgA Vasculitis) in Spanish individuals irrespective of the HLA-DRB1 status. Arthritis Res Ther 2015; 17: 102.

15. Heineke MH, Ballering AV, Jamin A, et al. New insights in the pathogenesis of immunoglobulin A vasculitis (Henoch-Schönlein purpura). Autoimmun Rev 2017; 16: 1246-1253.

16. Aleyd E, Heineke MH, van Egmond M. The era of the immunoglobulin A Fc receptor FcalphaRI; its function and potential as target in disease. Immunol Rev 2015; 268: 123-138.

17. Suzuki H, Raska M, Yamada K, et al. Cytokines alter IgA1 O-glycosylation by dysregulating C1GalT1 and ST6GalNAc-II enzymes. J Biol Chem 2014; 289: 5330-5339.

18. Suzuki H, Fan R, Zhang Z, et al. Aberrantly glycosylated IgA1 in IgA nephropathy patients is recognized by IgG antibodies with restricted heterogeneity. J Clin Invest 2009; 119: 1668-1677.

19. Novak J, Rizk D, Takahashi K, et al. New Insights into the Pathogenesis of IgA Nephropathy. Kidney Dis 2015; 1: 8-18.

20. Yang YH, Wang SJ, Chuang YH, et al. The level of IgA antibodies to human umbilical vein endothelial cells can be enhanced by TNF- $\alpha$ treatment in children with Henoch-Schönlein purpura. Clin Exp Immunol 2002; 130: 352-357.

21. Belizna C, Duijvestijn A, Hamidou M, et al. Antiendothelial cell antibodies in vasculitis and connective tissue disease. Ann Rheum Dis 2006; 65: 1545-1550.

22. Ghersetich I, Buggiani G, Brazzini B, et al. Cutaneous small-vessel vasculitis. Gital Dermatol Venereol 2004; 139: 389-413.

23. Roos A, Bouwman LH, van Gijlswijk-Janssen DJ, et al. Human IgA activates the complement system via the mannan-binding lectin pathway. J Immunol 2001; 167: 2861-2868.

24. Kimura S, Takeuchi S, Soma Y. Raised serum levels of interleukins 6 and 8 and antiphospholipid antibodies in an adult patient with Henoch-Schönlein purpura. Clin Exp Dermatol 2013; 38: 730-736.

25. Yang Z, Liang Y, Xi W, et al. Association of increased serum IL-33 levels with clinical and laboratory characteristics of systemic lupus erythematosus in Chinese population. Clin Exp Med 2011; 11: 75-80.

26. Chen T, Jia R, Guo Z, et al. Elevated serum interleukin-33 levels in patients with Henoch-Schönlein purpura. Arch Dermatol Res 2013; 305: 173-177.

27. Wang YB, Shan NN, Chen O, et al. Imbalance of interleukin-18 and interleukin-18 binding protein in children with Henoch-Schönlein purpura. J Int Med Res 2011; 39: 2201-2208.

28. Jen HY, Chuang YH, Lin SC, et al. Increased serum interleukin-17 and peripheral Th17 cells in children with acute Henoch-Schönlein purpura. Pediatr Allergy Immunol 2011; 22: 862-868.

29. Rigante D, Castellazzi L, Bosco A, et al. Is there a crossroad between infections, genetics, and Henoch-Schönlein purpura? Autoimmun Rev 2013; 12: 1016-1021.

30. Min Z, Garcia RR, Murillo M, et al. Vancomycin-associated Henoch-Schönlein purpura. J Infect Chemother 2017; 23: 180-184.

31. Holder SM, Joy MS, Falk RJ. Cutaneous and systemic manifestations of drug-induced vasculitis. Ann Pharmacother 2002; 36: 130-147.

32. Watanabe T. Henoch-Schönlein purpura following influenza vaccinations during the pandemic of influenza A (H1N1). Pediatr Nephrol 2011; 26: 795-798. 
33. Jariwala S, Vernon N, Shliozberg J. Henoch-Schönlein purpura after hepatitis A vaccination. Ann Allergy Asthma Immunol 2011; 107: 180-181.

34. Mitsui H, Shibagaki N, Kawamura T, et al. A clinical study of Henoch-Schönlein Purpura associated with malignancy. J Eur Acad Dermatol Venereol 2009; 23: 394-401.

35. Blanco R, González-Gay MA, Ibánez D, et al. Henoch-Schönlein purpura as a clinical presentation of small cell lung cancer. Clin Exp Rheumatol 1997; 15: 545-547.

36. Angelier AS, Petit L, Wynckel A, et al. Schoenlein-Henoch purpura as a presentation of squamous cell bronchial carcinoma. Rev Mal Respir 2011; 28: 372-376.

37. Nozato K, Morishima Y, Furuta J, et al. A case of Henoch-Schönlein purpura which was difficult to distinguish from a skin rash associated with gefitinib. Nihon Kokyuki Gakkai Zasshi 2010; 48: 529-534.

38. Jamrozik A, Sybilski A, Pohorecka M, et al. Zespół Schönleina-Henocha - nowe wyzwania diagnostyczne w starej chorobie. Pediatr Med Rodz 2012; 8: 214-221.

39. Trnka P. Henoch-Schönlein purpura in children. J Paediatr Child Health 2013; 49: 995-1003.

40. Bluman J, Goldman RD. Henoch-Schönlein purpura in children: limited benefit of corticosteroids. Can Fam Physician 2014; 60: $1007-1010$

41. Jauhola O, Ronkainen J, Koskimies O, et al. Clinical course of extrarenal symptoms in Henoch-Schonlein purpura: a 6-month prospective study. Arch Dis Child 2010; 95: 871-876.

42. Saulsbury FT. Clinical update: Henoch-Schönlein purpura. Lancet 2007; 369: 976-978

43. Trapani S, Micheli A, Grisolia F, et al. Schonlein purpura in childhood: epidemiological and clinical analysis of 150 cases over a 5 -year period and review of literature. Semin Arthritis Rheum 2005; 35: 143-153.

44. García-Porrúa C, Calviño MC, Llorca J, et al. Henoch-Schönlein purpura in children and adults: clinical differences in a defined population. Semin Arthritis Rheum 2002; 32: 149-156.

45. Özkaya AK, Güler E, Çetinkaya A. Henoch-Schönlein purpura complicated by acalculous cholecystitis and intussusception, and following recurrence with appendicitis. Paediatr Int Child Health 2016; 36: 157-159.

46. Huang DY, Li Q, Jiang KR, et al. Henoch-Schönlein Purpura: A Rare Cause of Recurrent Acute Pancreatitis. Chin Med J (Engl) 2016; 129: 2510-2511.

47. Kumar L, Singh S, Goraya JS, et al. Henoch Schonlein purpura: The Chandigarh experience. Indian Pediatr 1998; 35: 19-25.

48. Ronkainen J, Nuutinen M, Koskimies O. The adult kidney 24 years after childhood Henoch-Schönlein purpura: a retrospective cohort study. Lancet 2002; 360: 666-670.

49. Watson L, Richardson AR, Holt RC, et al. Henoch schonlein purpura - a 5-year review and proposed pathway. PLoS One 2012; 7 : e29512.

50. Zhao YL, Liu ZJ, Bai XM, et al. Obesity increases the risk of renal involvement in children with Henoch-Schönlein purpura. Eur J Pediatr 2015; 174: 1357-1363.

51. Narchi H. Risk of long term renal impairment and duration of follow up recommended for Henoch-Schonlein purpura with normal or minimal urinary findings: a systematic review. Arch Dis Child 2005; 90: 916-920.

52. Modi S, Mohan M, Jennings A. Acute Scrotal Swelling in Henoch-Schonlein Purpura: Case Report and Review of the Literature. Urol Case Rep 2016; 6: 9-11.

53. Dos Santos D, Langer FW, Dos Santos T, et al. Posterior reversible encephalopathy syndrome as a complication of Henoch-Schönlein purpura in a seven-year-old girl. Scott Med J 2017; 62: 34-37.
54. Hwang JJ, Ahn J, Kim KP, et al. Henoch-Schönlein Purpura With Muscle Involvement, Presenting as Myositis. J Clin Rheumatol 2017; 23: 60-62.

55. Michas G, Grigoriou K, Syrigos D, et al. A rare cause of myocarditis resulting in acute heart failure in the setting of Henoch-Schönlein purpura. Hellenic J Cardiol 2017; 58: 439-442.

56. Chen JY, Mao JH. Henoch-Schönlein purpura nephritis in children: incidence, pathogenesis and management, World J Pediatr 2015; 11: 29.

57. Bluman J, Goldman RD. Henoch-Schönlein purpura in childrenLimited benefit of corticosteroids. Can Fam Physician 2014; 60: 1007-1010.

58. Jauhola O, Ronkainen J, Koskimies O, et al. Clinical course of extrarenal symptoms in Henoch-Schonlein purpura: a 6-month prospective study. Arch Dis Child 2010; 95: 871-876.

59. Chartapisak W, Opastirakul S, Hodson EM, et al. Interventions for preventing and treating kidney disease in Henoch-Schönlein purpura (HSP). Cochrane Database Syst Rev 2009; 3: CD005128.

60. Weiss PF, Klink AJ, Localio R, et al. Corticosteroids may improve clinical outcomes during hospitalization for Henoch-Schönlein purpura. Pediatrics 2010; 126: 674-681.

61. Saulsbury FT. Henoch-Schonlein Purpura in children: report of 100 patients and review of the literature. Medicine 1999; 78: 395-409. 